\title{
APPLICATION OF ANTHROPODYNAMIC DUMMIES FOR EVALUATING THE IMPACT OF VEHICLE SEAT VIBRATIONS UPON HUMAN BODY
}

\author{
Tomasz Lech Stańczyk, Andrzej Zuska \\ Kielce University of Technology, Department of Automotive Vehicles and Transportation, Kielce, Poland \\ e-mail: a.zuska@tu.kielce.pl
}

\begin{abstract}
The paper presents the anthropodynamic dummy constructed at the Department of Automotive Vehicles and Transportation of the Kielce University of Technology, Kielce, Poland. The dummy is shown at the concept and design stages, and as a final construction. The first part of the study presents structural and dynamic requirements, and also the structure and construction selected for the dummy. The vertical dynamics of the body of a seated human is accounted for by conducting detailed analysis of the variation range of mass parameters and of the dummy elastic and damping parameters. The second part of the study presents the results of experimental simulations performed for the dummy.
\end{abstract}

Keywords: anthropodynamic dummy, vibratory comfort

\section{Introduction}

Initially, the measurements of transfer of vibrations by vehicle seats required participation of human subjects exposed to vibrations. The research results obtained in this way were far from satisfactory due to a significant variety of people's individual body features. Moreover, such measurements require input functions that must be safe for humans. Therefore, for ethical and safety reasons, it is advisable to conduct evaluation of vehicle seats without people being subject to vibrations. On the other hand, using stiff mass or a sand bag instead of a living person fails to ensure results that are satisfactorily consistent with real conditions (Griffin, 1990; Łomako et al., 1998; Mansfield and Griffin, 1996). Much better results can be obtained when the human subject is replaced with a dummy imitating dynamic reactions of a seated person. An example of such dummies is the Memosik. Information about impedance, measured under buttocks of a seated person as well as about the head-seat acceleration transmittance are useful in building the dummies. Memosik I was intended for tests at the 1-50 Hz frequency range. An adequately formed base and low centre of gravity ensure dummy stability during tests (Knoblauch et al., 1995). Memosik 1 dummy was the basis for Memosik II model which is intended for tests at the 0.5-30 Hz frequency range, which is typical for analyzing vibrational comfort in passenger vehicles (Knoblauch, 1992). Memosik III model was based on Memosik II, in which the degrees of freedom were reduced from five to three (Cullmann and Wölfel, 1998). Two subsequent dummy models: Memosik IV (Wölfel, 2006) and Memosik V (Mozaffarin et al., 2008) are active dummies, made on the basis of a passive dummy. Memosik IV enables conduction of tests in vertical direction, whereas Memosik V additionally enables tests in longitudinal and lateral directions.

Using dummies is justified by the requirement of comparability and objectivity of the results. In the course of comparative studies of several constructional solutions of seats, after some time, people change their position to a more comfortable one, stiffen their bodies due to weariness, etc. It distorts the research results. Dummies, on the other hand, manifest no such behaviour. 


\section{Construction of anthropodynamic dummy}

The construction of an anthropodynamic dummy presented in Fig. 1 is based upon the model with four degrees of freedom, which imitates propagation of vertical vibrations to selected body parts of a sitting person (Fig. 2).

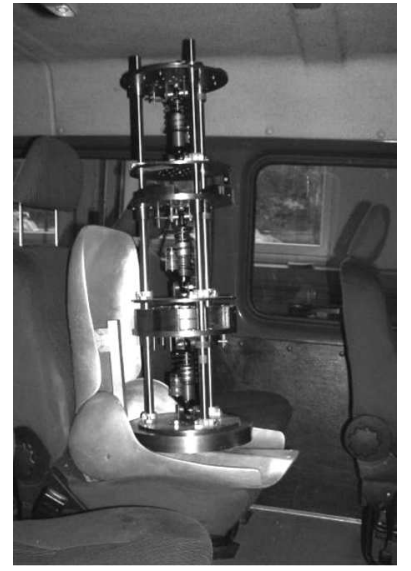

Fig. 1. Anthropodynamic dummy on a passenger seat

By means of four masses, the anthropodynamic model imitates four selected parts of the human body:

- mass $m_{1}$ imitates mass of the head,

- mass $m_{2}$ imitates mass of the pectoral girdle, chest and its internal organs and arms,

- mass $m_{3}$ imitates mass of the internal organs, abdominal cavity, diaphragm and abdominal walls,

- mass $m_{4}$ imitates mass of the spine, pelvis, thighs, forearms and hands.

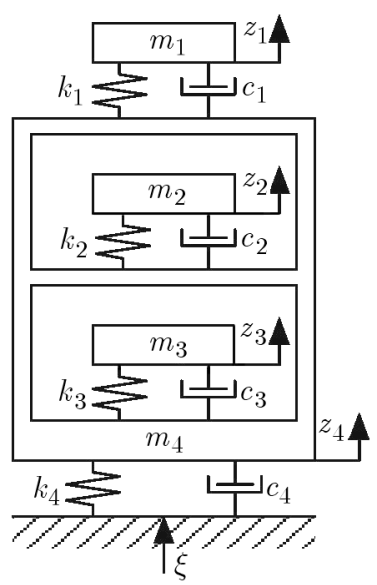

Fig. 2. Anthropodynamic model of a sitting human

The base of the dummy (imitating buttocks) and the support (imitating human back) connected with the basis with a hinged grip is made of epoxy resin. The weight of those elements accounts for 6 percent of the total dummy weight and it has not been taken into consideration in the studies.

The dummy frame consists of guides, fixed and moving discs, clamps and line bearings. The frame is fixed to the base, in which six evenly spaced sockets have been made. Mounted in the sockets are rubber springy-damping elements (Fig. 3), and the entire construction rests upon the dummy base. 


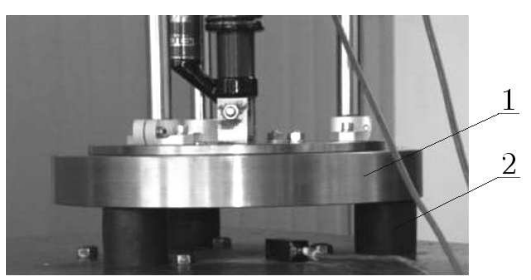

Fig. 3. The base of the dummy frame with rubber spring-damping elements mounted in six sockets: 1 - frame basis, 2 - rubber element

The guides are made of metal rollers. The accurate position of guides is ensured by fixed metal discs connected with the guides by aluminium clamps. Three moving discs slide on the guides, imitating respectively mass of the first (head), second (chest) and the third (abdomen) part of the human body (Fig. 4). Mounting the suitable set of weights to vibrating elements enables one to imitate individual anthropometric features of different body types.
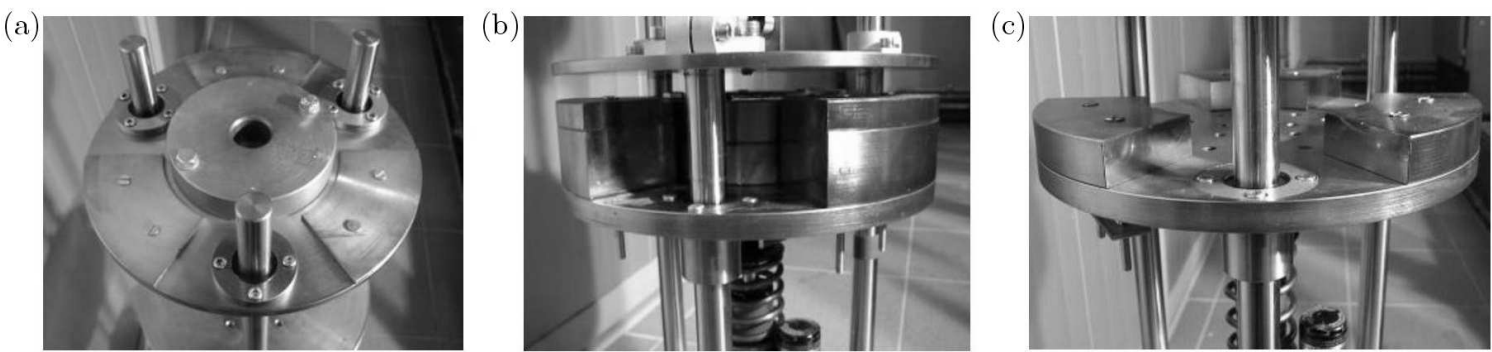

Fig. 4. Moving discs imitating the respective body parts with a sample sets of weights: a - disc 1 , $\mathrm{b}-\operatorname{disc} 2, \mathrm{c}-\operatorname{disc} 3$

The moving discs have holes where longitudinal bearings are mounted. The bearings ensure minimal resistance to motion for the discs moving on the guides.

Each moving disc is connected to the dummy frame by means of a spring-damper system consisting of a damper and a spring (Fig. 5).

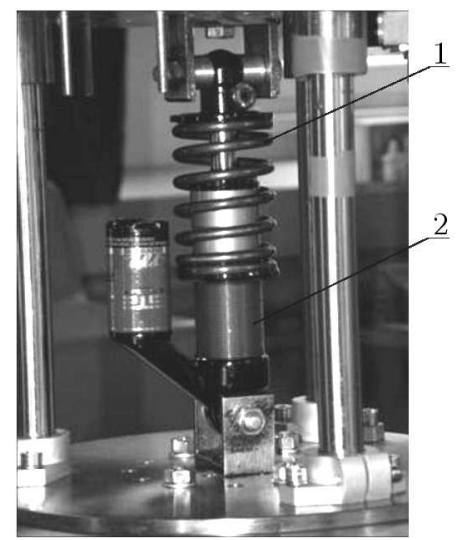

Fig. 5. Spring-damper system: 1 - spring, 2 - damper

Properly selected sets of weights, dampers, springs and rubber elements enable the dummy to imitate the vertical dynamics of various types of the human body.

\subsection{Selection of spring-damping elements of the anthropodynamic dummy and identification of their parameters}

One of the fundamental requirements to be met by the anthropodynamic dummy is the accurate imitation of the vertical dynamics of a seated human body. For that purpose, a number 
of tests has been carried out on a stand constructed on the basis of MTS components (Zuska, 2007). The objective of the tests was to determine the transmittance of acceleration for three configurations (output-input): head-seat, chest-seat and abdomen-seat in the selected group of people, Fig. 6 (Zuska, 2007).

Upon the transmittance courses for medians and quantiles 0.1 and 0.9 of the modules designated in laboratory tests, the stiffness $\left(k_{1}, k_{2}, k_{3}, k_{4}\right)$, damping $\left(c_{1}, c_{2}, c_{3}, c_{4}\right)$ and mass parameters of the model presented in Fig. 2 are identified.
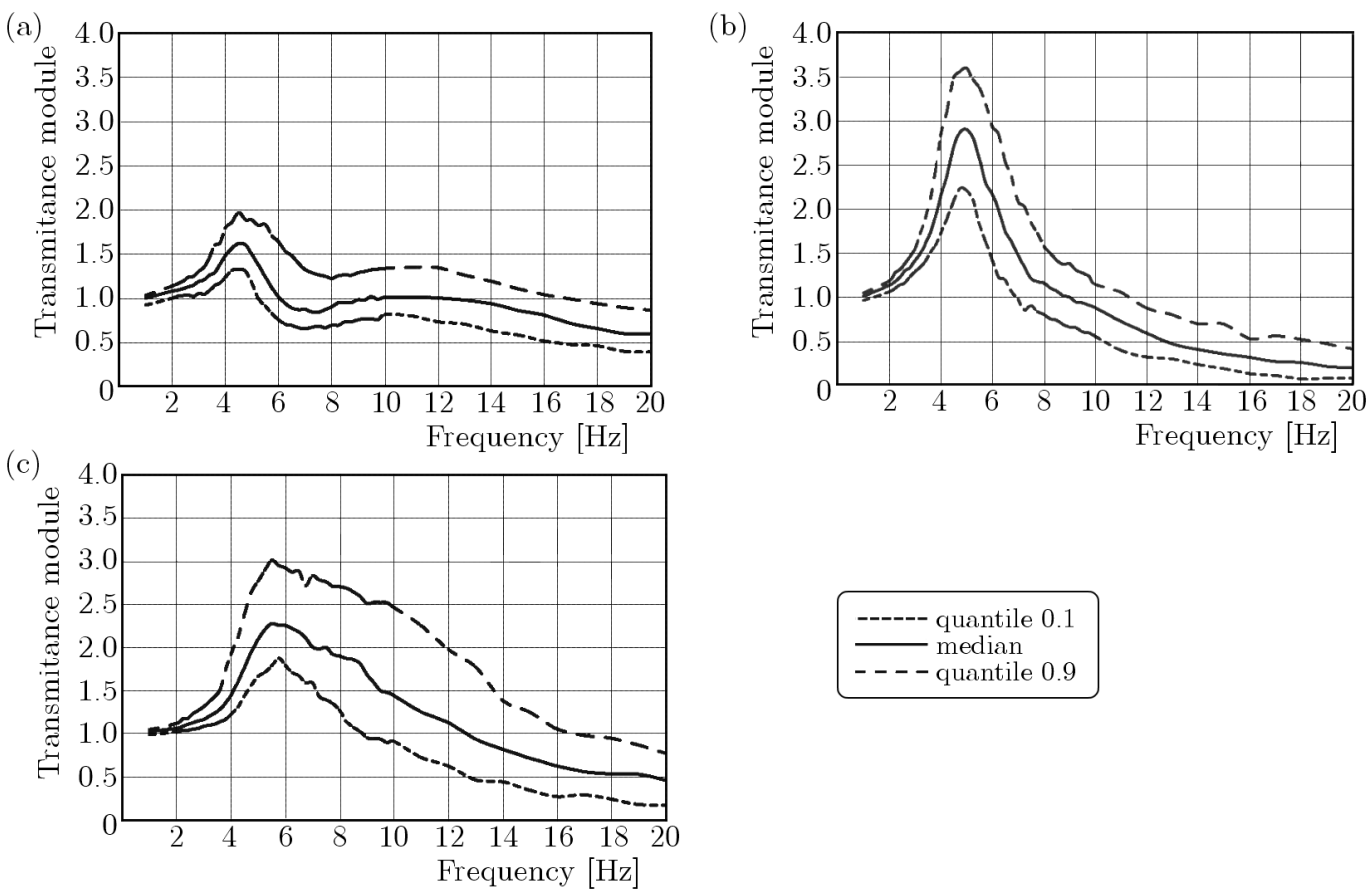

Fig. 6. Courses of transmittance modules: (a) head - seat, (b) chest - seat, (c) abdomen - seat

Before the selection of the supple elements, a number of constructional requirements to be met was adopted. The requirements have been established upon the assumed dimensions of the dummy and the identified parameters of stiffness and damping elements of the mathematic model (Table 1). For the obtained stiffness and damping coefficients, a $15 \%$ toleration has been permitted.

Table 1. Parameters of the anthropodynamic model

\begin{tabular}{|c|c|c|c|c|}
\hline \multicolumn{2}{|l|}{ Parameter } & Quantile 0.1 & Median & Quantile 0.9 \\
\hline \hline \multirow{4}{*}{ Mass $[\mathrm{kg}]$} & $m_{1}$ & 4.83 & 5.77 & 7.43 \\
\cline { 2 - 5 } & $m_{2}$ & 13.75 & 16.43 & 21.17 \\
\cline { 2 - 5 } & $m_{3}$ & 6.75 & 8.06 & 10.38 \\
\cline { 2 - 5 } & $m_{4}$ & 33.05 & 39.40 & 50.90 \\
\hline \multirow{2}{*}{$\begin{array}{c}\text { Stiffness } \\
\text { coefficient } \\
{[\mathrm{N} / \mathrm{m}]}\end{array}$} & $k_{1}$ & 3898 & 5098 & 7169 \\
\cline { 2 - 5 } & $k_{2}$ & 14856 & 18124 & 24181 \\
\cline { 2 - 5 } & $k_{3}$ & 11350 & 14761 & 20644 \\
\cline { 2 - 5 } & $k_{4}$ & 508863 & 398800 & 279187 \\
\hline \multirow{2}{*}{$\begin{array}{c}\text { Damping } \\
\text { coefficient } \\
{[\mathrm{N} \cdot \mathrm{s} / \mathrm{m}]}\end{array}$} & $c_{1}$ & 200 & 212 & 302 \\
\cline { 2 - 5 } & $c_{2}$ & 254 & 257 & 349 \\
\cline { 2 - 5 } & $c_{3}$ & 197 & 209 & 245 \\
\cline { 2 - 5 } & $c_{4}$ & 13385 & 1113 & 17 \\
\hline
\end{tabular}


The tests aimed at determining:

- stiffness coefficient of the springs,

- damping coefficient of the dampers,

- stiffness and damping coefficients of the rubber elements,

and have been carried out on the testing stand adopted for such tests (construction based on a hydraulic actuator manufactured by MTS). They which enabled imitation of the working parameters of dampers, springs and rubber elements (Table 2) as well as recording of the following signals:

- displacement of the plate with the fixed rubber element or spring and displacement of the holder with the fixed cylinder of the damper,

- compressive force affecting the rubber element or spring and damping force of the shock absorber.

Table 2. Working parameters of spring-damping systems

\begin{tabular}{|l|c|c|c|c|}
\hline \multirow{2}{*}{ Parameter } & \multicolumn{4}{|c|}{ System } \\
\cline { 2 - 5 } & No. 1 & No. 2 & No. 3 & No. 4 \\
\hline \hline Frequency $[\mathrm{Hz}]$ & $1-20$ & $1-20$ & $1-20$ & $1-20$ \\
\hline Amplitude $[\mathrm{mm}]$ & $0.00-2.73$ & $0.00-4.49$ & $0.00-2.15$ & $0.05-0.62$ \\
\hline Pre-load load $[\mathrm{kg}]$ & 5.77 & 16.43 & 8.06 & 69.66 \\
\hline
\end{tabular}

\subsubsection{Selection of coil springs and identification of their stiffness coefficient}

Taking into consideration the constructional assumptions and stiffness coefficients $\left(k_{1}, k_{2}\right.$, $k_{3}$ ) identified for the mathematical model, a pre-selection of springs has been made.

For every pre-selected spring, a test has been carried out to identify their actual stiffness coefficient (Table 3).

Table 3. Parameters of the 50-centile dummy springs

\begin{tabular}{|c|c|c|c|c|}
\hline \multicolumn{4}{|c|}{ Stiffness coefficient $[\mathrm{N} / \mathrm{m}]$} & \multirow{2}{*}{$\begin{array}{c}\text { Deviation from } \\
\text { the assumed } \\
\text { value [\%] }\end{array}$} \\
\hline \hline$k_{1 m 50}$ & 5098 & 5300 & 5495 & 7.8 \\
\hline$k_{2 m 50}$ & 18124 & 17781 & 20249 & 11.7 \\
\hline$k_{3 m 50}$ & 14761 & 15556 & 17230 & 16.7 \\
\hline
\end{tabular}

The obtained values of stiffness coefficients $k_{1 m 50}$ and $k_{2 m 50}$ differ from the assumed values by less than 15 percent and fall within the assumed range of toleration, whereas the value of the $k_{3 m 50}$ stiffness coefficient differs from the assumed one by 16.7 percent and does not meet the 15-percent toleration range. However, a decision has been made to keep the spring and not to reject it until the entire dummy has been examined.

\subsubsection{Selection of dampers and identification of their damping coefficient}

Taking into consideration the constructional requirements:

- damper maximum length $250 \mathrm{~mm}$,

- minimum stroke of the piston rod $10 \mathrm{~mm}$, 
as well as damping coefficients $\left(c_{1}, c_{2}, c_{3}\right)$ identified for the mathematical model, a pre-selection of dampers has been made.

The actual characteristics of the selected dampers differed from the required ones. Therefore, constructional changes have been made, which included:

- using oil of various density and viscosity,

- replacing the valves installed in the piston by suitable discs with openings (ducts, bypasses).

After each constructional change in the dampers, a test has been performed to determine the work diagram, which served as a basis for identifying the damping coefficient of the tested dampers (Fig. 7).

The obtained values of the damping coefficient (Table 4) differ from the assumed values by less than 15 percent.

Table 4. Parameters of dampers of the 50-centile dummy

\begin{tabular}{|c|c|c|c|}
\hline \multicolumn{3}{|c|}{ Damping coefficient $[\mathrm{N} \cdot \mathrm{s} / \mathrm{m}]$} & $\begin{array}{c}\text { Deviation from the } \\
\text { assumed value [\%] }\end{array}$ \\
\hline \hline Designation & Assumed value & Determined value & 5.0 \\
\hline \hline$c_{1 m 50}$ & 212 & 222.65 & 2.9 \\
\hline$c_{2 m 50}$ & 257 & 264.36 & 8.4 \\
\hline$c_{3 m 50}$ & 209 & 191.54 & \\
\hline
\end{tabular}

\subsubsection{Selection of rubber elements and identification of their damping $\left(c_{4}\right)$ and stiffness $\left(k_{4}\right)$ coefficients}

The rubber element in the mathematical model is presented as a Kelvin-Voigt spring-damping element.

Taking into consideration the constructional requirements:

- rubber elements have cylindrical shape of a $50 \mathrm{~mm}$ diameter,

- height of the rubber elements falls within the 20-100 $\mathrm{mm}$ range,

- quantity of the rubber elements to ensure the dummy stability is either three, four or six items,

as well as the damping $\left(c_{4}\right)$ and stiffness $\left(k_{4}\right)$ coefficients identified for the mathematical models, a pre-selection of the rubber elements has been made (Table 5) followed by identification of actual values of those coefficients.

Table 5. Initial parameters of the selected rubber elements

\begin{tabular}{|c|c|c|c|}
\hline $\begin{array}{c}\text { Hardness } \\
{\left[{ }^{\circ} \mathrm{Sh}\right]}\end{array}$ & $\begin{array}{c}\text { Diameter } \\
{[\mathrm{mm}]}\end{array}$ & $\begin{array}{c}\text { Height } \\
{[\mathrm{mm}]}\end{array}$ & Shape \\
\hline \hline $40,50,60,70,80,90$ & 50 & $20,40,60$ & cylinder \\
\hline
\end{tabular}

For every pre-selected rubber element, a test has been carried out to determine its static characteristics (Fig. 8) upon which the stiffness and damping coefficients for the tested elements have been identified.

An assumption has been made that the characteristics of the rubber element $f(\lambda, \dot{\lambda})$ may be presented in an additive form

$$
f(\lambda, \dot{\lambda})=f_{s}(\lambda)+f_{t}(\dot{\lambda})
$$

where $f_{s}(\lambda)$ is the stiffness component of the characteristics, $f_{t}(\dot{\lambda})$ - the damping component of the characteristics. 
(a)

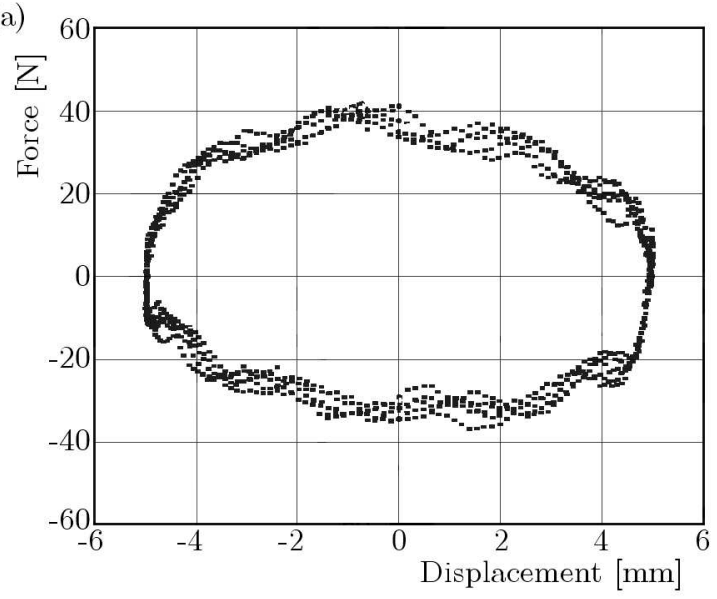

(c)

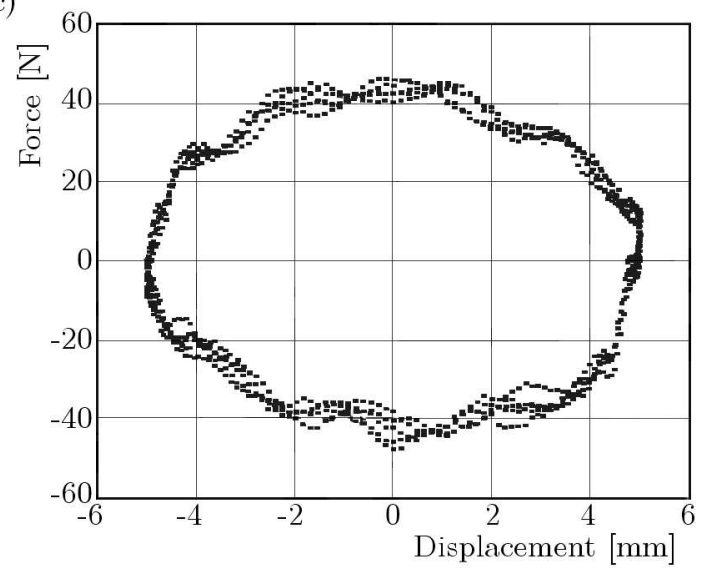

(e)

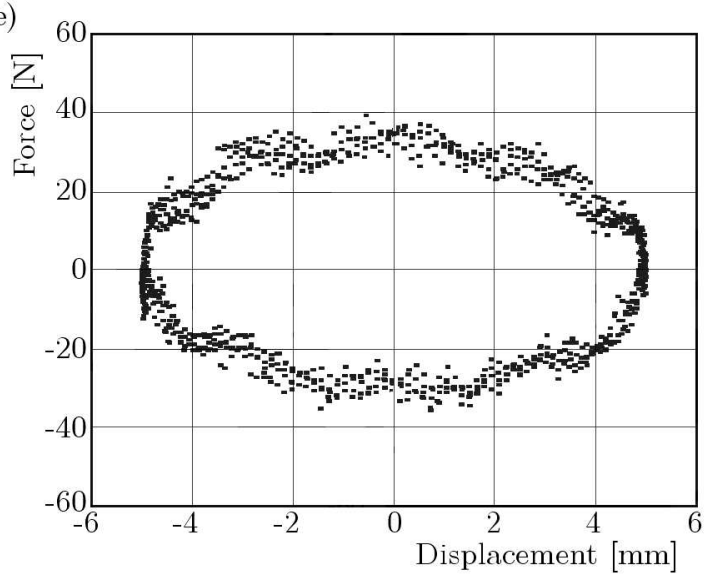

(b)

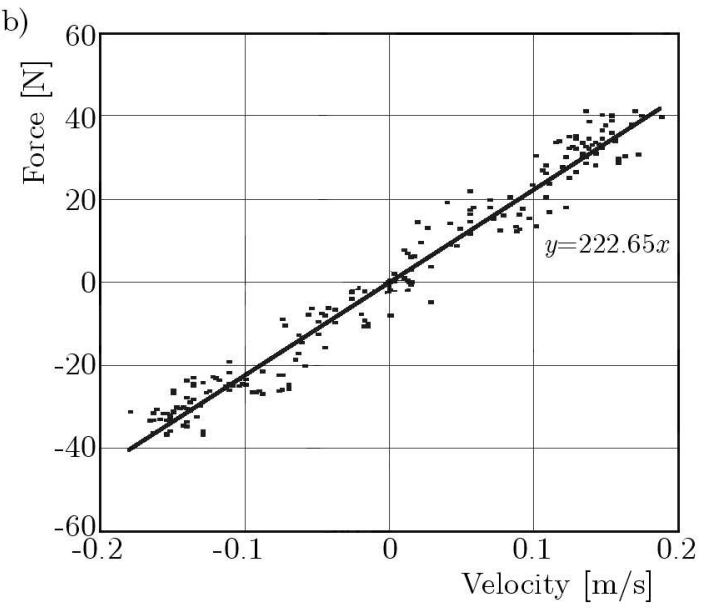

(d)

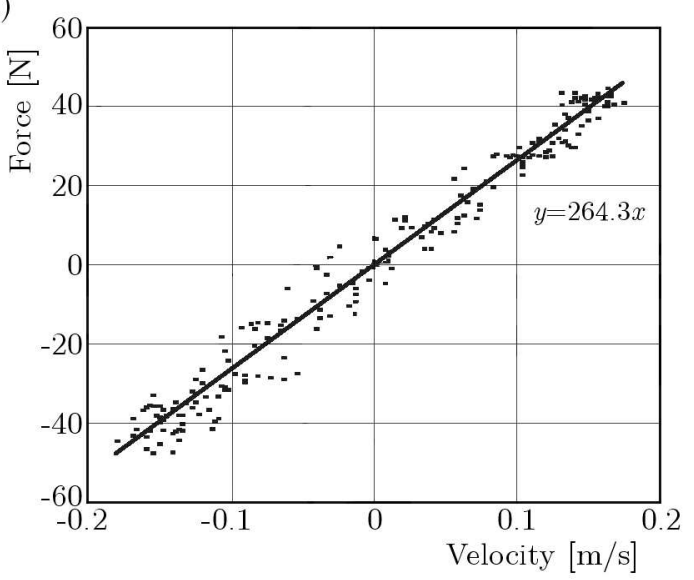

(f)

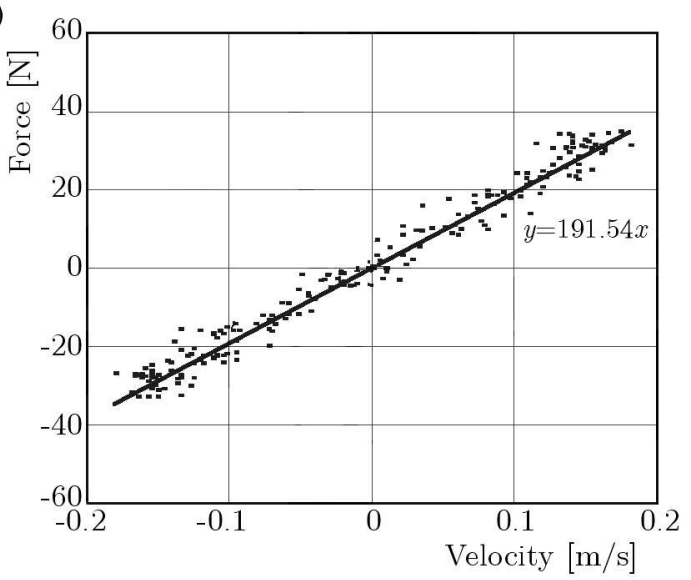

Fig. 7. Work diagrams and the actual characteristics of dampers utilised in the 50-centile anthropodynamic dummy: (a) work diagram of disc 1 support, (b) damping characteristics of disc 1 support, (c) work diagram of disc 2 support, (d) damping characteristics of disc 2 support, (e) work diagram of disc 3 support, (f) damping characteristics of disc 3 support

Given a relatively small nonlinearity of the frame axis within the range of actual work parameters (pre-load load $-23 \mathrm{~kg}$, deflection amplitude $-0.62 \mathrm{~mm}$ ) it has been assumed that it has a linear shape (Fig. 8b, Fig. 9). The slope of the linear regression line of the frame axis is the required stiffness coefficient of the rubber element (Fig. 11).

Since the velocity of the damper piston rod is known for every point in the diagram (Fig. 10a), it is possible to determine the damping characteristics $f_{t}(\dot{\lambda})$ (Fig. 10b). 
(a)

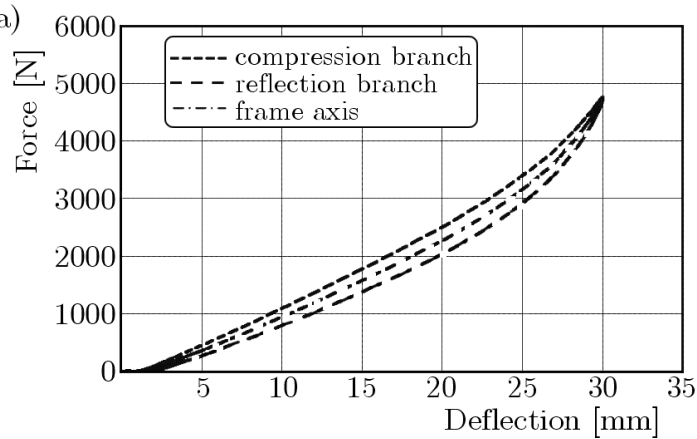

(b)

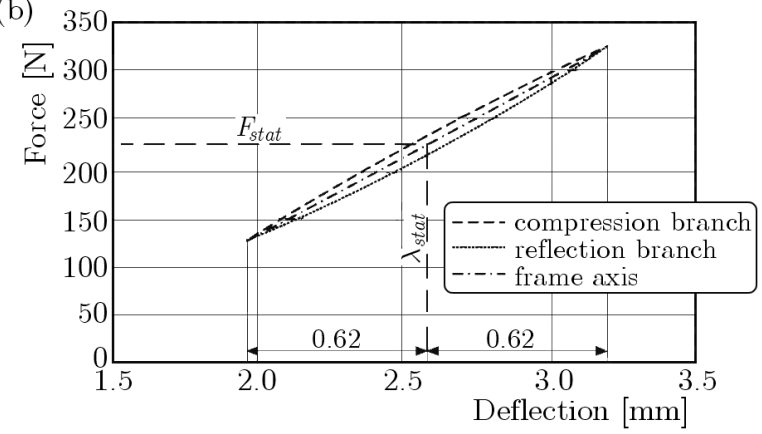

Fig. 8. Characteristics of selected rubber elements: (a) for wide range of loads, (b) made for actual work parameters (actual load range)

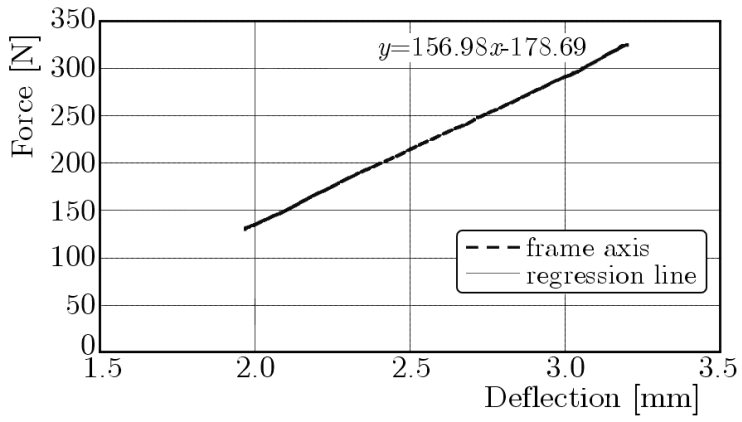

Fig. 9. Stiffness characteristics of the rubber element

(a)

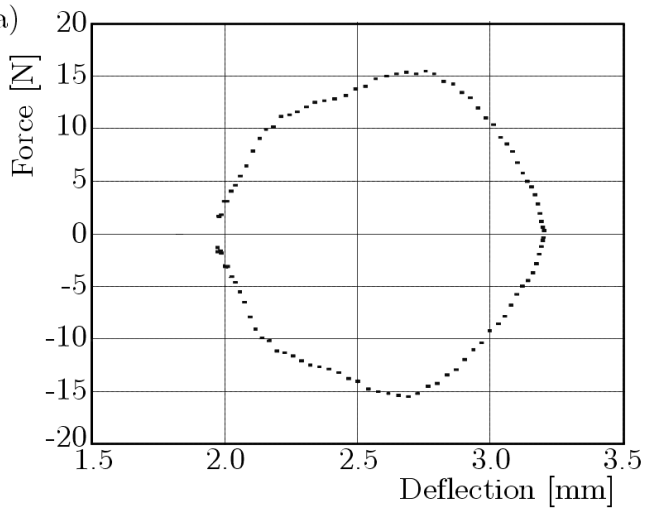

(b)

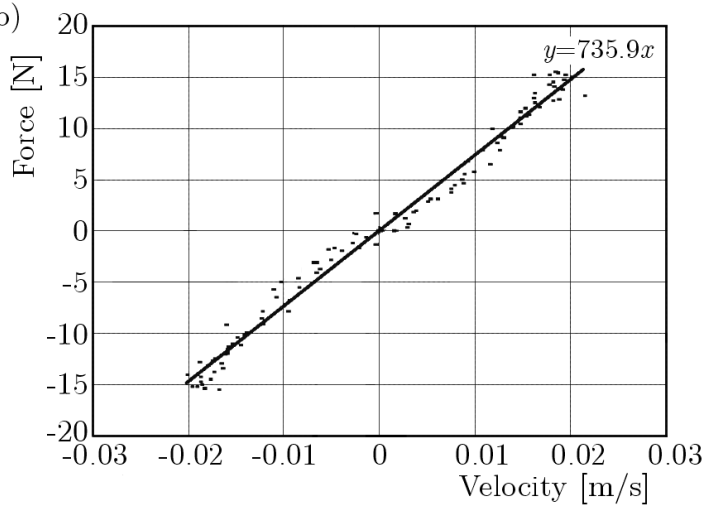

Fig. 10. Characteristics of the rubber element without stiffness component and the damping characteristics based upon it: (a) work diagram of the rubber element, (b) damping characteristics

The slope of the linear regression line of the damping characteristics is the required damping coefficient of a single rubber element (Table 6).

The obtained value of the stiffness coefficient differs from the assumed value by 18 percent and meets the 20 percent tolerance range, whereas the value of the damping coefficient differs from the assumed value by $98 \%$ and fails to meet the 20 percent tolerance range. It has been decided to keep the rubber elements and not to reject it until the entire dummy has been examined. 
Table 6. Parameters of the selected rubber elements

\begin{tabular}{|l|c|c|c|c|}
\hline Coefficient & Designation & $\begin{array}{c}\text { Assumed } \\
\text { value }\end{array}$ & $\begin{array}{c}\text { Determined } \\
\text { value }\end{array}$ & $\begin{array}{c}\text { Deviation from the } \\
\text { assumed value [\%] }\end{array}$ \\
\hline \hline Damping $[\mathrm{N} \cdot \mathrm{s} / \mathrm{m}]$ & $c_{4 m 50}$ & 1113 & 2207.94 & 98 \\
\hline Stiffness $[\mathrm{N} / \mathrm{m}]$ & $k_{4 m 50}$ & 398800 & 470940 & 18 \\
\hline
\end{tabular}

\section{Anthropodynamic dummy - the results of verification tests}

The value measured in the tests has been the acceleration of three moving discs of the dummy (disc 1, disc 2 and disc 3) and the acceleration of the surface of the plate on which the dummy is placed.

The recorded acceleration signals have been used for determining the transmittance of three input-output systems: plate - disc 1, plate - disc 2, plate - disc 3 .

The list of the test results conducted for the dummy and the median transmittance courses, determined for 80 tested people, are presented in the Fig. 11.
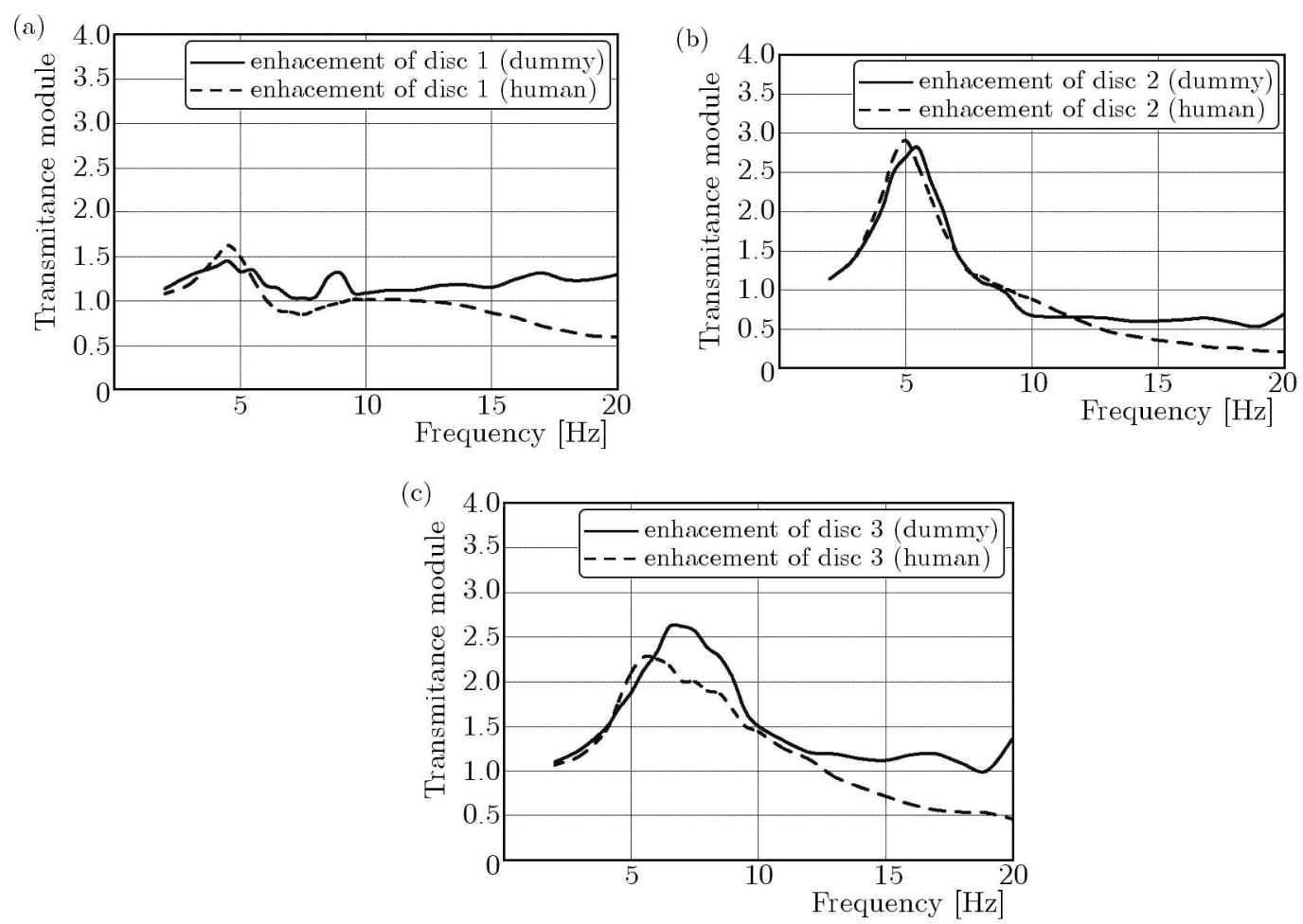

Fig. 11. Results of the experiment - testing of the dummy and the median of tests of 80 people:

(a) transmittance of disc 1 and body part 1, (b) transmittance of disc 2 and body part 2,

(c) transmittance of disc 3 and body part 3

The highest compatibility is displayed by the transmittance courses of disc 2 and body part 2 . As presented in the diagram of transmittance courses, the highest enhancement is observed for frequencies of $5 \mathrm{~Hz}$ and $5.5 \mathrm{~Hz}$, respectively. The difference between the maximum enhancement values for these characteristics is 3.3 percent. The courses of the curves for other frequency ranges presented in the diagrams are also very similar.

As indicated by the transmittance courses of body part 1 and disc 1, the highest enhancement for both courses occurs for the same frequency of $4.5 \mathrm{~Hz}$. The difference of enhancement values for this frequency is 10.6 percent. The characteristics have similar courses in the frequency range between 3 and ca. $12 \mathrm{~Hz}$. Above the latter frequency, there are increasing discrepancies between the characteristics. 
The transmittance courses for body part 3 and disc 3 are the least compatible. The highest enhancement for both these courses exists in different resonant frequencies, with a $1.5 \mathrm{~Hz}$ offset with respect to one another. The difference between the maximum enhancement values is 15 percent. In this instance, the characteristics display the highest compatibility in two frequency ranges: 1-6 $\mathrm{Hz}$ and 9-12.5 Hz.

\section{Conclusion}

Testing vibrational comfort in vehicles may involve either the entire body of a sitting person or its selected parts. For ethical reasons, as well as for ensuring safety and repeatability of obtained results, people are increasingly often replaced with anthropodynamic dummies. The structure of such dummies, used for testing vibrational comfort, should reflect the structure of a sitting human being while taking into consideration the analysed body parts for which test are to be carried out.

The results of the conducted experimental tests indicate that at least three areas of the human body should be distinguished in a dummy, as each one is characterised by a different resonance frequency and various levels of acceleration enhancement. The structure of the dummy presented in this paper comprises these parts. The proposed amount of degrees of freedom is a compromise between obtaining the most accurate representation of the human body structure and the constructional limitations which occurred as the dummy was being built.

The symmetric construction of the dummy prevents the occurrence of forces producing unwanted longitudinal or lateral rocking which, in consequence, increases the dummy stability. Properly formed buttocks and the back ensure the adequate imitation of the distribution of individual pressures produced by a vehicle driver or passenger. The construction of the dummy enables one to imitate mass structures of people of various weight (slim, normal weight, obese).

A significant qualitative and quantitative similarity between the characteristics obtained in laboratory tests of the dummy transmittance and the respective characteristics of human subjects proves that dummies (with a construction based upon the results of the experiment) may be successfully applied to evaluate the impact of vibrations on vehicle passengers.

The assumed solution enables a fairly easy reconfiguration of the dummy to imitate the 10th and the 90th percentile of the weights of tested people.

\section{References}

1. Cullmann A., Wölfel H.P., 1998, Komfortbewertung und Sitzprüfung mittels des Schwingungsdummys MEMOSIK, Fachtagung, Haus der Technik, Essen

2. Griffin M.J., 1990, Handbook of Human Vibration, Academic Pres, London

3. KNoblauch J., 1992, Entwicklung und Bau eines physikalischen Schwingungsmodells des sitzenden Menschen, Dissertation, Shaker Verlag

4. Knoblauch J., Wölfel H.P., Buck P., 1995, Ein Schwingungsdummy des sitzenden Menschen, ATZ - Automobiltechnische Zeitschrift, 97, 10

5. Łomako D.M., Stańczyk T. L., WyręBkiewicz A., 1998, Zagadnienie komfortu jazdy w samochodach z pasywnym zawieszeniem fotela kierowcy, VI Międzynarodowa Konferencji "Pojazdy Samochodowe. Problemy Rozwoju, Jakości, Eksploatacji AUTOPROGRES", 1

6. Mansfield N.J., Griffin M.J., 1996, Vehicle seat dynamics measured with an anthropodynamic dummy and human subjects, Proceedings of Inter-Noise 96, Liverpool UK 
7. Mozaffari A., Pankoke S., Wölfel H.P., 2008, MEMOSIK V - An active dummy for determining three-directional transfer functions of vehicle seats and vibration exposure ratings for the seated occupant, International Journal of Industrial Ergonomics, $\mathbf{3 8}$

8. Nélisse H., Boileau P.É., Rakheja S., Patra S., Boutin J., 2006, Évaluation de mannequins anthropodynamiques destines aux essais de vibrations des sièges en laboratoires; Études et Recherches, Raport R479

9. WÖLfEL H.P., 2006, Numerical models and hardware dummies for simulating whole body vibration of human - an overview, Proceedings of the First American Conference on Human Vibration, West Virginia, U.S.A., DHHS (NIOSH) Publication No. 2006-140 June

10. ZuskA A., 2005, Identyfikacja rozprzestrzeniania się pionowych drgań w organizmie siedzącego człowieka, Teka Komisji Motoryzacji PAN, Oddz. Kraków, 29/30

11. ZuskA A., 2007, Analiza porównawcza rozprzestrzeniania się pionowych drgań w organizmach osób o różnej budowie ciała, Logistyka, 3

12. Zuska A., Stańczyk T.L., 2005, Stanowisko do symulacyjnych badań podukładu fotel-kierowca, Prace Naukowe TRANSPORT, Wydawnictwo Politechniki Radomskiej, 21, 1, 149-158 